\title{
KUALITAS PELAYANAN RUMAH SAKIT 'AISYIYAH PARIAMAN TERHADAP KEPUASAN PESERTA JKN (JAMINAN KESEHATAN NASIONAL)
}

\section{SERVICE QUALITY MANAGEMENT ANALYSIS OF AISYIYAH HOSPITAL TOWARDS SATISFACTION OF JKN PARTICIPANTS (NATIONAL HEALTH GUARANTEE)}

\author{
M. Zaky Mubarak Lubis dan Siti Hanafiah R. \\ Fakultas Ekonomi dan Bisnis Islam UIN Imam Bonjol Padang \\ Sungai Bangek Kelurahan Balai Gadang, Kec. Koto Tangah Padang \\ zakylubis@uinib.ac.id,buruangabung27@gmail.com
}

Naskah diterima 20 Mei 2020, di-review 03 Juni 2020, disetujui 30 Juni 2020

\begin{abstract}
This research is a quantitative study, which aims to analyze services quality to the satisfaction of inpatient JKN participants at Aisyiyah Hospital, Pariaman. This research was conducted on July to August 2019 by using a survey design. The sample was 100 patients taken by applying purposive sampling techniques. Data were analyzed through servqual method and IPA analysis. The research results showed overall services dimension, between services provided by 'Aisyiyah Pariaman Hospital and patient expectations, shows a gap of 2,308. This score was categorized in a high group which means the service is already good. It was based on importance analysis in quadrant $A$ (physical evidence, empathy, and guarantee); in quadrant $D$ (a reliability dimension); and in quadrant $C$ (a responsiveness dimension).
\end{abstract}

Keywords: Quality of Service, Patient Satisfaction., Hospital

\begin{abstract}
Abstrak: Penelitian ini merupakan penelitian kuantitatif, yang bertujuan untuk menganalisis kualitas pelayanan terhadap kepuasan peserta JKN rawat inap Rumah Sakit Aisyiyah Pariaman. Penelitian ini dilakukan pada bulan Juli hingga Agustus 2019, menggunakan desain survey yaitu mengambil sampel dari satu populasi. Dalam penelitian ini menggunakan sampel sebanyak 100 pasien melalui penyebaran kuisioner.Teknik pengambilan sampel dalam penelitian ini menggunakan teknik Purposive Sampling.Dan dilanjutkan dengan metode servqual dan analisis IPA.Hasil penelitian ini menunjukkan bahwa dimensi pelayanan secara keseluruhan, antara pelayanan yang diberikan Rumah Sakit 'Aisyiyah Pariaman dengan harapan pasien menunjukkan gap sebesar 2.308, skor ini dikategorikan dalam kelompok tinggi yang berarti pelayanannya sudah baik. Dan pada Importance Analysis yang terdapat pada kuadran A bukti fisik, empati dan jaminan. Pada kuadran D terdapat dimensi keandalan. Pada kuadran $\mathrm{C}$ terdapat dimensi daya tanggap.
\end{abstract}

Kata Kunci: Kualitas Pelayanan, Kepuasan Pasien, Rumah Sakit

\section{PENDAHULuAN}

Cepuasan pelanggan merupakan tujuan utama disebabkan karena kepuasan nasabah merupakan bagian penting dalam mempertahankan citra organisasi di masyarakatluas. Dampaknya, pelayanan terhadap pelanggan harus ditingkatkan. Hal tersebut sangat penting karena peranan pelanggan yangsangat besar dalam kontribusi pendapatan secara langsung. (Febriana, 2016).

Dalam rangka menciptakan kepuasan tersebut maka setiap organisasi akan berupaya 
memberikan pelayanan terbaik pada pelanggan, tak terkecuali rumah sakit. Rumah sakit berupaya memberikan pelayanan maksmimal untuk melayani problem kesehatan masyarakat. Salah satu upaya tersebut adalah pemberlakuan fasilitas BPJS JKN bagi masyarakat. Hal tersebut dilakukan sebagai upaya menjangkau akses fasilitas kesehatan bagi semua kalangan. (Novrialdi, 2017)

Berdasarkan Undang-Undang Nomor 24 Tahun 2011 Tentang BPJS Kesehatan, dijelaskan bahwa seluruh penduduk Indonesia wajib menjadi peserta BPJS Kesehatan. Peserta adalah setiap orang, termasuk orang asing yang bekerja paling singkat 6 (enam) bulan di Indonesia, yang telah membayar iuran. Hal ini bertujuan agar seluruh masyarakat Indonesia dapat mengakses fasilitas kesehatan yang ada di Rumah Sakit.

Akan tetapi dalam aplikasinya pelayanan rumah sakit berbasis BPJS memiliki implikasi berbeda dalam pelayanan. Penelitian yang dilakukan oleh Novrialdi (2017) tentang pelayanan BPJS di RSUD Siak menunjukkan bahwa pelayanan kesehatan bagi pasien BPJS di RSUD Siak tahun 2016 masih rendah. Hal ini didasarkan pada ketepatan waktu pelayanan, sistem pelayanan berbasis komputer yang masih lemah sehingga berkas tidak terkontrol dengan baik, bahkan hilang sehingga tidak dapat dipertanggungjawabkan kepada pasien. Hal tersebut menunjukkan bahwa masih terdapat kelemahan dalam pelayanan yang diberikan terhadap masyarakat pengguna BPJS.

Dalam penelitian lain yang dilakukan Romaji dan Nasihah (2018) menunjukkan bahwa ada perbedaan antara pelayanan yang dirasakan pasien BPJS dan Non BPJS. Dimana pelayanan yang diberikan kepada pasien non BPJS dalam pandangan pasien lebih baik dibandingkan dengan pasien BPJS. Hal tersebut disebabkan dari perbedaan pola pembiayaan antara sistem BPJS dan non BPJS. Jika sistem pembayaran non BPJS bersifat langsung maka sistem pembayaran BPJS bersifat talangan. Hal ini menjadi dasar perbedaan pelayanan yang dirasakan oleh pasien.

Adanya kelemahan dari pelayanan yang dirasakan masyarakat terhadap pelayanan pasien BPJS menjadi sebuah problem bagi pemangku kesehatan. Hal tersebut disebabkan karena secara logika, jumlah pasien BPJS jauh lebih besar dibandingkan dengan BPJS yang diperkuat dengan adanya undang-undang. Hal tersebut semestinya menjadi perhatian bagi rumah sakit dalam melaksanakan pelayanan kesehatan. Apalagi jumlah pasien berbasis BPJS memperlihatkan kecendrungan meningkat di rumah sakit yang ada.

Secara logis, peningkatan jumlah pelanggan beririsan dengan peningkatan jumlah pelayanan. Semakin baik layanan yang diberikan akan membuat pelanggan merasa betah dan berniat untuk berkunjung kembali. Sebaliknya pelayanan yang buruk akan berimplikasi pada rendahnya minat pasien untuk kembali menggunakan jasa tersebut (Widada, 2017), (Affandi, Zaki, \& Azmeri, 2017), (Khoirista, Yulianto, \& Mawardi, 2015), (Rohaeni \& Marwa, 2018), (Yansah, Hartono, \& Hariyono, 2013), (Assegaff, 2009), (Taman, Sukirno, Sari, Setiawan, \& Pustikaningsih, 2013), (Moha \& Loindong, 2016). 
Hal ini juga berlaku untuk rumah sakit. Jika pelayanan yang diberikan baik maka pasien akan berminat untuk kembali sedangkan sebaliknya jika pelayanan yang diberikan buruk maka pasien tidak akan berminat lagi menggunakan jasa rumah sakit tersebut.
Salah satu rumah sakit yang mengalami peningkatan jumlah pengguna jasa BPJS JKN adalah Rumah Sakit Aisyiyah Pariaman. Berdasarkan data dari pihak rumah sakit per Juni 2019 terjadi peningkatan jumlah pasien rawat inap dibandingkan juni 2018.

Tabel 1. Jumlah Peserta Rawat Inap JKN RS Aisyiyah Pariaman

\begin{tabular}{|l|l|l|l|}
\hline \multirow{2}{*}{ No } & \multirow{2}{*}{ Bulan } & \multicolumn{2}{c|}{ Peserta rawat JKN } \\
\cline { 3 - 4 } & & \multicolumn{2}{c}{2018} \\
\hline 1 & Januari & 395 & 669 \\
\hline 2 & Februari & 403 & 675 \\
\hline 3 & Maret & 400 & 636 \\
\hline 4 & April & 399 & 724 \\
\hline 5 & Mei & 413 & 679 \\
\hline 6 & Juni & 385 & 574 \\
\hline
\end{tabular}

Sumber: Rumah Sakit Aisyiyah Pariaman Juli 2019

Adanya peningkatan jumlah pasien mengindikasikan adanya kepuasan dalam diri pasien terhadap pelayanan RSUD Pariaman. Hal ini bertolak belakang dengan dua penelitian awal yang menujukkan kurangnya kepuasan pasien BPJS terhadap pelayanan yang didapatkan. Untuk melihat secara lebih jauh bagaimana pelayanan yang diberikan seiring dengan peningkatan jumlah pasien BPJS di RSUD Pariman maka akan diteliti tentang kualitas pelayanan RSUD Pariaman terhadap kepuasan yang dirasakan pengguna fasilitas BPJS Kesehatan.

\section{KERANGKA KONSEPTUAL}

\section{Grand Theory}

Problematika kepuasan pelanggan dan kualitas pelayanan tercakup dalam pembahasan manajemen pemasaran. Manajemen pemasaran memegang peranan penting dalam perkembangan perusahaan. Tindakan ini meliputi proses analisis, perencanaan, pelaksanaan, dan pengawasan mencakup jasa, gagasan dan juga barang. Tujuan dari adanya manajemen pemasaran adalah mencapai kepuasan bagi pihak yang terkait.

Dalam tindakan ini terdapat proses pembuatan, penawaran dan pertukaran antar individu berdasarkan keperluan masing-masing. (Kottler \& Lane, 2008,h.139)

\section{Middle Theory}

Kualitas layanan adalah taksiran pemberian layanan sesuai dengan harapan pelanggan (Wijaya, 2011). Kualitas pelayanan adalah kesuaian realita layanan dengan harapan pelanggan dan bertujuan melebihi ekspektasi pelanggan (Tjiptono, 2011).

Kepuasan konsumen merupakan bentuk ekspresi yang keluar sebagai efek dari layanan yang diberikan dibandingkan dengan harapan. Perasaan senang timbul saat ekspektasi melebihi harapan sebaliknya, perasaan kecewa timbul saat ekspektasi berada dibawah harapan.(Bailia, 
Soegoto, \& Loindong, 2014). Kepuasan pelanggan merupakan suatu indicator untuk melihat trend keberhasilan bisnis dimasa depan berdasarkan tanggapan konsumen (Assauri, 2012). Kepuasan konsumen adalah layanan yang dirasakan konsumen dari pemberi jasa sesuai dengan harapan (Nitisemito, 2001).

\section{Gambar 1. Kerangka Teori}

\begin{tabular}{|c|c|c|c|c|c|}
\hline Variabel & Dimensi & Indikator & & & \\
\hline $\begin{array}{l}\text { Kualitas } \\
\text { pelayanan }\end{array}$ & $\begin{array}{l}\text { Bukti Fisik } \\
\text { Empati } \\
\text { Keandalan } \\
\text { Daya } \\
\text { tanggap } \\
\text { Jaminan }\end{array}$ & $\begin{array}{l}\text { Penampilan fisik, } \\
\text { peralatan, personel, dan } \\
\text { materi komunikasi. } \\
\text { Kesediaan untuk peduli, } \\
\text { memberi perhatian } \\
\text { pribadi bagi pelanggan. } \\
\text { Kemampuan untuk } \\
\text { melaksanakan jasa yang } \\
\text { dijanjikan dengan } \\
\text { terpercaya dan akurat. } \\
\text { Kemampuan untuk } \\
\text { membantu pelanggan } \\
\text { danmeberikanjasa } \\
\text { dengan cepat. } \\
\text { Pengetahuan dan } \\
\text { kesopanan karyawan } \\
\text { dankemampuan } \\
\text { mereka untuk } \\
\text { menimbulkan } \\
\text { kepercayaan dan } \\
\text { keyakinan. }\end{array}$ & $\rightarrow \mid \begin{array}{c}\mathrm{T} \\
\mathrm{A} \\
\mathrm{N} \\
\mathrm{G} \\
\mathrm{G} \\
\mathrm{A} \\
\mathrm{P} \\
\mathrm{A} \\
\mathrm{N} \\
\mathrm{P} \\
\mathrm{A} \\
\mathrm{S} \\
\mathrm{I} \\
\mathrm{E} \\
\mathrm{N}\end{array}$ & +2 & $\rightarrow \begin{array}{c}\mathrm{K} \\
\mathrm{E} \\
\mathrm{P} \\
\mathrm{U} \\
\mathrm{A} \\
\mathrm{S} \\
\mathrm{A} \\
\mathrm{N} \\
\mathrm{P} \\
\mathrm{A} \\
\mathrm{S} \\
\mathrm{I} \\
\mathrm{E} \\
\mathrm{N}\end{array}$ \\
\hline
\end{tabular}

Sumber : Netisemito, 2001

Salah satu pendekatan untuk mengukur kualitas pelayanan adalah model SERVQUAL (Service Quality) yang dikembangkan oleh Parasuraman, Zeithaml dan Berry. Pendekatan ini dibangun atas perbandingan dua faktor utama, yaitu persepsi pelanggan atas layanan yang nyata mereka terima (perceived service) dengan layanan yang sesungguhnya diharapkan (expected service). Apabila layanan yang diberikan melebihi harapan maka ia bernilai baik atau positif sedangan apabila layanan dibawah harapan maka bernilai buruk atau negatif. Untuk dapat mengukur hal tersebut maka terdapat lima dimensi yang menjadi fokus pada kualitas jasa (Sevice Quality) yaitu berwujud (tangible), keandalan (reliability), ketanggapan (responsiveness), jaminan dan kepastian (assurance), dan empati (empathy) (Abdurahman, Junaidi, \& Aminuyati)

\section{METODE PENELITIAN}

\section{Jenis Penelitian}

Penelitian ini adalah jenis penelitian deskriptif kuantitatif. Penelitian ini memberikan deskripsi kepuasan peserta BPJS dari segi penilaian dimensi tangible, reliability, responsiveness, assurance, dan emphaty di Rumah Sakit Aisyiyah Pariaman dengan menggunakan metode analisis Servqual dan analisis Importance.

\section{Sumber Data}

Terdapat dua sumber data dlam penelitian ini yaitu data primer dan data sekunder. Data primer 
adalah kuisoner yang diberikan pada pasien BPJS JKN rawat inap di Rumah Sakit Aisyiyah Pariaman. Data sekunder berasal dari buku teks, jurnal dan lainnya.

\section{Populasi dan Sampel}

Populasi dalam penelitian ini adalah jumlah peserta JKN (Jaminan Kesehatan Nasional) pasien rawat inap Rumah Sakit Aisyiyah dari bulan Januari 2019 hingga Juni 2019 sejumlah 4.112 orang. Penghitungan sampel dalam penelitian ini sebagai berikut:(Bungin, 2008, p.105)

$$
n=\frac{N}{N(d)^{2}+1}
$$

\section{Keterangan:}

$n$ : Jumlah sampel yang dicari

$N$ : Jumlah Populasi

$d$ : Nilai Presisi (sebesar $90 \%$ atau $\mathrm{a}=0,1$ )

Dengan demikian maka dari jumlah populasi 4.112 diperoleh ukuran sampel sebesar 97,64 atau 97 sampel penelitian. Penulis membulatkan menjadi 100 sampel.

\section{Kriteria Responden}

Teknik penarikan sampel yang digunakan pada penelitian ini menggunakan metode purposive sampling dengan kriteria sebagai berikut:

1. Pasien rawat inap peserta JKN Rumah Sakit Aisyiyah Pariaman.

2. Usia antara 17-65 tahun.

3. Pasien dalam kondisi tidak kritis.

4. Pasien bersedia mengisi kuisioner yang diberikan.

\section{Teknik Analisis Data}

1. Verifikasi Data

Melakukan cross check terhadap jawaban responden.

2. Menghitung Nilai Jawaban Responden Hasil jawaban responden yang dikalkulasikan merupakan persentase dari karakteristik responden dan hasil jawaban responden atas pertanyaan yang diajukan dan kemudian diolah menggunakan statistik.

3. Pengukuran SERVQUAL / Analisis GAP Penelitian ini membandingkan informasi antara layanan yang diterima dengan harapan yang dipersepsikan oleh pelanggan. Untuk menghitung skor SERVQUAL digunakan rumus sebagai berikut: (Tjiptono \& Chandra, Service, Quality, and Satisfaction, 2016). Skor SEVRQUAL (gap) = Skor Persepsi - Skor Harapan.

Selanjutnya untuk identifikasi dari hasil servqual digunakan metode ImportancePerformance Analysis (IPA). Importance Performance Analysis (IPA) adalah sebuah cara untuk melihat ukuran kinerja utama yang menjadi tolak ukur kepuasan pelanggan pada sebuah perusahaan. Dengan rumus sebagai berikut : (Wibawa, 2015)

$$
\bar{x}_{\text {kin } \theta \text { rja }}=\frac{\sum \mathrm{x}}{\mathrm{N}}
$$

\section{Dimana:}

$\mathrm{x}$ : Rata-rata penilaian persepsi responden

$\mathrm{N}$ : jumlah reponden

$\mathrm{x}$ : Jumlah skor persepsi masing-masing variabel 
JURNAL IMARA

$$
\bar{y}_{\text {harapan }}=\frac{\sum y}{\mathrm{~N}}
$$

Dimana:

y : Rata-rata penilaian harapan responden

$\mathrm{N}$ : jumlah reponden

$\mathrm{x}$ : Jumlah skor harapan masing-masing variabel

Langkah lanjutan adalah membuat diagram kartesius perbandingan antara persepsi dan harapan sebagai berikut:

Gambar 2. Diagram Kartesius Analisis IPA

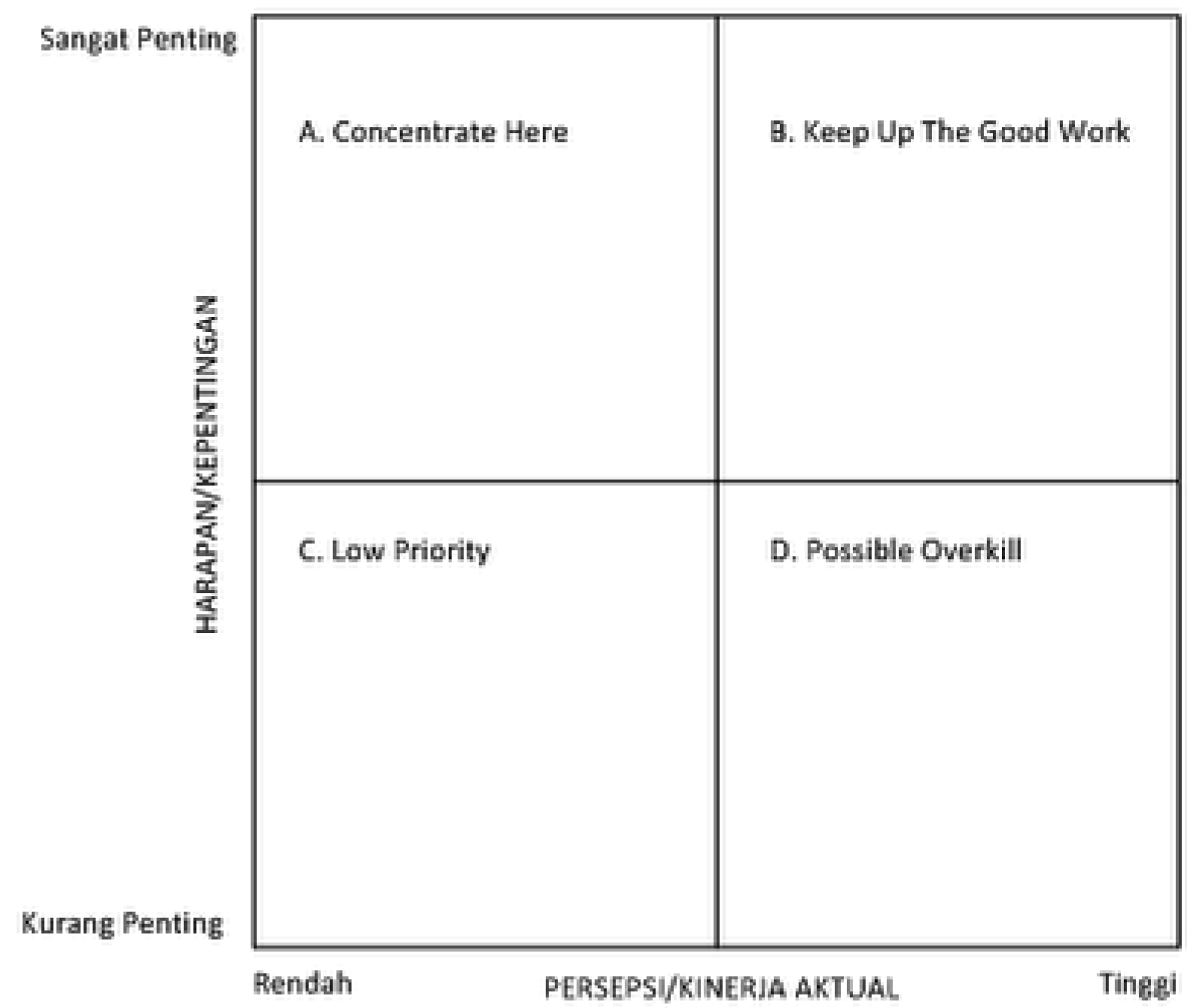

Sumber : (Wibawa, 2015)

\section{PEMBAHASAN DAN HASIL}

Hasil Analisis GAP

Respon pasien rawat inap terhadap kualitas pelayanan kesehatan di Rumah Sakit 'Aisyiyah
Pariaman mencakup dimensi bukti fisik, empati, keandalan, daya tanggap, dan jaminan sebagai berikut :

36 || M. Zaky Mubarak Lubis Dan Siti Hanafiah R. 
Gambar 3. Hasil GAP SERVQUAL

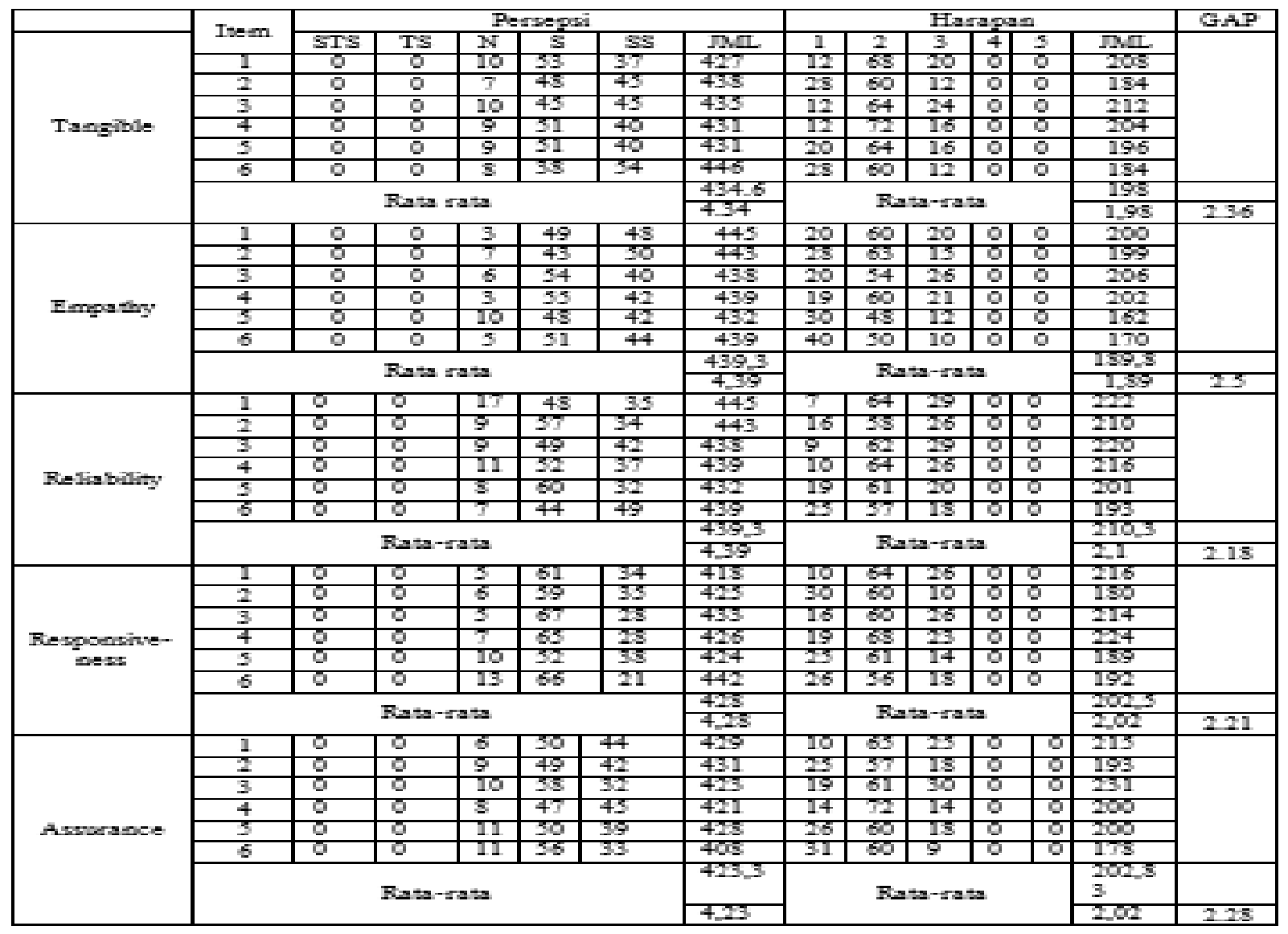

Sumber: Data diolah

Dari hasil analisis gap terlihat bahwa variabel bukti fisik menghasilkan gap sebesar 2,36. Gap ini termasuk ke dalam klasifikasi tinggi-baik. Lalu, variabel empati menghasilkan gap sebesar 2,5. Gap ini termasuk dalam klasifikasi sangat tinggisangat baik. Variabel keandalan memperoleh gap sebesar 2,18. Gap ini termasuk ke dalam klasifikasi tinggi-baik. Variabel daya tanggap memperoleh gap sebesar 2,21. Gap ini termasuk ke dalam klasifikasi tinggi-baik. Variabel jaminan menghasilkan gap sebesar 2,18. Gap ini termasuk ke dalam klasifikasi tinggi-baik.

Selisih antara persepsi dan harapan menjelaskan tingkat kepuasan pasien, paling rendah terjadi pada saat persepsi jauh dibawah harapan. Begitu juga sebaliknya, dalam tabel dapat kita lihat rata-rata persepsi dari setiap dimensi pelayanan berkisar antara 4,23 hingga 4,39. Dimana rata-rata tertinggi diperoleh pada dimensi empati $(4,39)$ dan yang terendah pada dimensi daya tanggap $(4,23)$. Untuk harapan rata-rata dimensi pelayanan berkisar antara 1,89 hingga 2,02. Yang tertinggi pada dimensi daya jaminan dan yang terendah pada dimensi empati.

Secara keseluruhan rata-rata persepsi dari setiap dimensi pelayanan sebesar 4,308, sedangkan harapan sebesar 2,142 sehingga menghasilkan gap sebesar 4,308 - 2,142= 2,166 . Dalam klasifikasi kepuasan gap ini termasuk klasifikasi tinggi. Dan dari 5 variabel 
kualitas pelayanan, variabel yang memberikan kepuasan yang sangat tinggi kepada konsumen yaitu variabel empati. Dimana gap empati diklasifikasikan sangat tinggi.

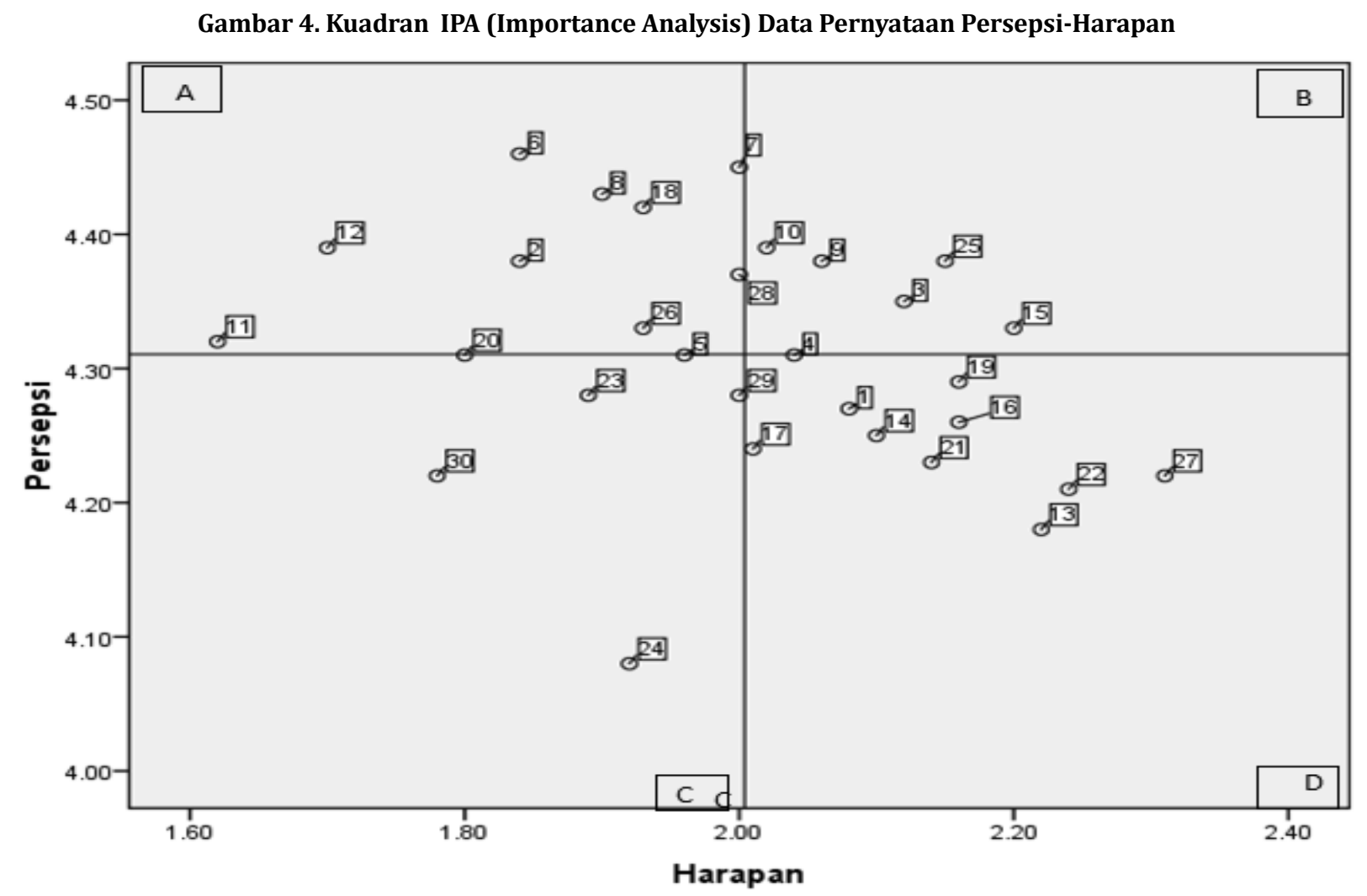

Sumber: Data diolah

Dari gambar 4.1 terlihat bahwa pernyataan nomor 2, 5, 6, 8, 11, 12, 18, 20 dan 26 terletak pada kuadran A. Dimana kuadran ini merupakan kuadran yang penting dan diharapkan oleh konsumen tetapi kondisi persepsi atau kinerja belum mencapai harapan konsumen. Misal pernyataan yang terdapat pada nomor 2 yaitu ruangan rawat inap Rumah Sakit Aisyiyah Pariaman bersih, ini maksudnya ruangan rawat inap merupakan kinerja yang penting tetapi belum begitu memuaskan sehingga pihak rumah sakit hendaknya memperbaiki dan meningkatkan pada layanan ini. Menurut Subagyo terdapat dimensi pelayanan yang dikenal dengan rater yang salah satunya yaitu bukti fisik indikatornya mencakup peralatan dan fasilitas yang lengkap serta gedung yang memadai dan nyaman (Dewi, 2016).

Pernyataan nomor 3, 4, 9, 10, 15 dan 25 terletak pada kuadran $B$, dimana kuadran ini merupakan kuadran yang penting. Karena harapan konsumen pada kuadran ini tinggi didukung dengan kinerja yang juga tinggi dan diharapkan sebagai faktor penunjang bagi kepuasan konsumen. Misalnya pada pernyataan nomor 3 yaitu dokter pada rawat inap Rumah Sakit Aisyiyah Pariaman berpenampilan rapi dan bersih. Hal ini maksudnya persepsi dan harapan pasien terhadap dokter telah sangat memuaskan dan hal ini perlu untuk dipertahankan.

Pernyataan nomor 7 dan 28 terletak diantara kuadaran A dan B. Ini menggambarkan bahwa 
nilai persepsi dan harapan mendekati kualifikasi sangat tinggi yang artinya hampir mendekati sangat memuaskan Jika dilihat, misal pernyataan nomor 7 yaitu rawat inap Rumah Sakit Aisyiyah Pariaman memberikan perhatian individual kepada pasien. Ini berarti bahwa layanan yang diberikan rumah sakit hampir mendekati sangat memuaskan. Dan dilihat dari pernyataan nomor 28 yaitu dokter pada rawat inap Rumah Sakit Aisyiyah Pariaman secara konsisten bersikap sopan terhadap pasien. Dari hasil wawancara dengan salah satu pasien bahwasanya tidak ada pasien yang tidak ditangani oleh dokter. Seandainya dokter spesialis belum datang, maka dokter umum siap menangani.

Pernyataan yang terletak pada kuadran C adalah pernyataan nomor 23,24 dan 30 , dimana kuadran ini mempunyai tingkat persepsi atau kinerja yang rendah sehingga dianggap kurang penting dan tidak terlalu diharapkan konsumen. Misal pernyataan nomor 23 yaitu perawat rawat inap Rumah Sakit Aisyiyah Pariaman bersedia membantu pasien. Ini berarti harapan pasien terhadap pelayanan yang berikan oleh Rumah Sakti Aisyiyah Pariaman belum memuaskan.
Pernyataan nomor 1, 13, 14, 16, 17, 19, 21, 22 dan 27 terletak pada kuadran D, dimana kuadran ini dianggap tidak terlalu penting dan tidak terlalu diharapkan oleh konsumen, hal ini terlihat dari rendahnya harapan konsumen terhadap pernyataan tersebut dan tingginya persepsi atau kinerja yang telah didapatkan konsumen. Misal pada pernyataan nomor 1 yaitu fasilitas fisik seperti bangunan dan ruangan rawat inap Rumah Sakit Aisyiyah Pariaman dalam kondisi baik. Ini berarti bangunan kondisi fisik Rumah Sakit Aisyiyah Pariaman dianggap kurang penting tetapi sangat memuaskan. Walau bagaimanapun, bangunan kondisi fisik menjadi salah satu daya tarik untuk mengunjungi Rumah Sakit Aisyiyah Pariaman.

Penyataan nomor 17 dan 29 terletak diantara kuadran C dan D. Misal, pernyataan nomor 29 yaitu perawat pada rawat inap Rumah Sakit 'Aisyiyah Pariaman secara konsisten bersikap sopan terhadap pasien. Ini berarti harapan dan kinerja yang diberikan hampir mendekati klasifikasi memuaskan. Walau dianggap atribut yang kurang penting.

Tabel 2. Importance-Performance Analysis (IPA) Plotting Data Masing-masing Indikator

\begin{tabular}{|l|l|l|}
\hline Indikator-indikator & Mean (p) & Mean (e) \\
\hline Bukti fisik & 4.34 & 1,98 \\
\hline Empati & 4.39 & 1.89 \\
\hline Keandalan & 4.28 & 2.18 \\
\hline Daya tanggap & 4.23 & 2.02 \\
\hline Jaminan & 4.30 & 2.02 \\
\hline Sum & 21.54 & 9.72 \\
\hline c.line & 4.308 & 2.142 \\
\hline
\end{tabular}

Sumber: Data diolah

Dari tabel 10. terlihat sangat jelas bahwa pada rata-rata persepsi pada dimensi empati memperoleh skor yang tertinggi $(4,39)$. Sedangkan pada harapan rata-rata terendah pada dimensi empati $(1,89)$ yang mengakibatkan memperoleh gap tertinggi $(2,5)$. Rata-rata persepsi pada dimensi daya tanggap memperoleh skor yang terendah $(4,23)$. Sedangkan pada harapan memperoleh skor 2,08. Dari tabel 
diatas terlihat juga rata-rata keseluruhan dari persepsi dari peneitian ini diperoleh skor 4,308 dan untuk harapan diperoleh skor 2,142 dengan gap 2,166 Dari gambar di atas terlihat bahwa variabel bukti fisik, empati dan jaminan terletak pada kuadran A yang berarti variabel ini sangat penting. Karena harapan dari variabel ini tinggi sedangkan persepsi atau kinerja yang dirasakan konsumen masih perlu ditingkatkan.

Rumah Sakit Aisyiyah Pariaman sebagai perusahaan yang bergerak dibidang jasa perlu memperhatikan pelayanan yang diberikan yang nantinya menentukan kepuasaan konsumen. Pada dimensi yang masih berada di kuadran A ditingkatan sehingga bergerak ke kuadaran B pada klasifikasi sangat memuaskan. Kalau hal ini tercapai maka akan terjadi peningkatan pasien dan bermuara pada peningkatan pendapatan.

Menurut Parasuraman dalam Tjiptono menyatakan bahwa bukti fisik berkenaan dengan daya tarik fasilitas fisik, perlengkapan, dan material yang digunakan perusahaan, serta penampilan karyawan. Dalam meningkatkan kepuasan pelanggan khususnya perusahaan jasa, para pelanggan akan banyak dipengaruhi oleh atribut-atribut yang digunakan oleh perusahaan jasa (Tjiptono \& Chandra, 2016). Dengan kata lain jika perusahaan dapat memberikan bukti fisik yang baik maka akan mendapat respon positif sehingga menimbulkan kepuasan.

Begitu juga dengan Empati berarti bahwa perusahaan memahami masalah para pelanggannya dan bertindak demi kepentingan pelanggan, serta memberikan perhatian personal kepada para pelanggan dan memiliki jam operasi yang nyaman.
Dengan kata lain jika perusahaan dapat memahami dan memberikan perhatian personal terhadap pelanggan maka akan memberikan respon positif sehingga menimbulkan kepuasan.

Menurut Parasuraman dalam Tjiptono Jaminan yakni perilaku para karyawan mampu menumbuhkan kepercayaan pelanggan terhadapperusahaan dan perusahaan bisa menciptakan rasa aman bagi para pelangganya (Tjiptono \& Chandra, 2016). Jaminan juga berarti parakaryawan selalu bersikap sopan dan menguasai pengetahuan dan keterampilan yang dibutuhkan untuk menangani setiap pertanyaan atau masalah pelanggan. Menumbuhkan kepercayaan konsumen terhadap perusahaan sulit dilakukan, oleh karena itu pihak Rumah Sakit 'Aisyiyah Pariaman untuk dapat mempertahankan dan meningkatkan kepercayaan pasien sehingga dapat meningkatkan kepuasan pasien pada saat ini.

Pada kuadran C, terdapat dimensi daya tanggap. Yang berarti pelayanan yang termasuk indikator ini menunjukkan atribut yang diangap kurang penting dan kurang memuaskan sehingga sebaiknya rumah sakit menjalankan sedang saja. Kinerja dan kepentingan pengguna layanan pada variabel ini berada pada tingkat rendah, sehingga organisasi belum perlu melakukan perbaikan.

Hal ini sesuai dengan teori yang dikemukakan oleh parasuraman dalam Tjiptono bahwa Daya tanggap berkenaan kesediaan dan kemampuan para karyawan untuk membantu para pelanggan dan merespon permintaan mereka, serta menginformasikan kapan jasa akan diberikan dan kemudian akan memberikan jasa secara cepat (Tjiptono \& Chandra, 2016). 
Variabel keandalan terletak pada kuadran D yang berarti variabel ini dianggap kurang penting tetapi sangat memuaskan. Hal ini dianggap berlebihan. Kinerja organisasi berada pada tingkat tinggi tetapi kepentingan konsumen terhadap kinerja variabel rendah. Rumah sakit sebagai perusahan yang menjual jasa tidak perlu melakukan perbaikan hanya perlu mempertahankan pelayan yang sudah diberikan.

\section{PENUTUP}

\section{Kesimpulan}

Berdasarkan analisis SERVQUAL (GAP) dimensi pelayanan secara keseluruhan, antara pelayanan BPJS yang diberikan oleh Rumah Sakit Aisyiyah Pariaman dengan harapan pasien rawat inap terhadap gap diperoleh skor sebesar 2,308. Skor ini dikategorikan dalam kelompok tinggi, artinya manajemen pengelolaan Rumah Sakit Aisyiyah Pariaman telah memuaskan. Pada Importance Analysis yang terdapat pada kuadran A bukti fisik, empati dan jaminan. Pada kuadran D terdapat dimensi keandalan. Pada kuadran C terdapat dimensi daya tanggap. Hal ini menunjukkan bahwa pelayanan yangdiberikan oleh Rumah Sakitterhadap pasien BPJS JKN telah memberikan kepuasan kepada pasien. Pihak rumah sakit telah mampu memfasilitasi masyarakat yang menggunakan BPJS seperti layaknya pasien non BPJS.

Sebagai implikasinya maka RSU Aisyiyah Pariaman harus mampu mempertahankan kualitas pelayanan yang telah diberikan kepada masyarakat dan berupaya meningkatkan layanan yang diberikan terutama dalam hal empati. Disebabkan bukti ini memiliki nilai GAP terbesar yang menunjukkan bahwa karyawan RSU Aisyayah memiliki kepedulian yang sangat besar pada pasien yang menjadi kunci utama dalam pelayanan pasien.

\section{Saran}

Melihat rata-rata skor GAP dalam dimensi kualitas pelayanan berada dalam kategori tinggi, Rumah Sakit 'Aisyiyah Pariaman sebaiknya tetap mempertahankan kondisi pelayanan pada saat sekarang agar dapat mempertahankan kepuasan pasien atau lebih meningkatkan kualitas pelayanan sehingga dapat memberikan kepuasan yang maksimal kepada pasien.

Selain itu, Rumah Sakit'Aisyiyah Pariaman perlu secara rutin mengamati pelayanannya agar dapat mempertahankan kelebihan-kelebihan yang ada dan selalu meningkatkan kualitas pelayanan pada variabel-variabel yangmasih kurangpenilaiannya atau menurut penilaian pasien belum sesuai dengan yang diharapkan oleh pasien. Hal ini bisa dilakukan dengan memperhatikan terhadap kebutuhan dan keinginan pasien. Peningkatan fasilitas sarana prasarana, jaminan rasa aman, nyaman, dan kepercayaan serta pelayanan yang dijanjikan secara cepat, akurat dan pasti sehingga akan meningkatkan kepuasan pasien.

\section{DAFTAR KEPUSTAKAAN}

Abdurahman, Junaidi, \& Aminuyati. (n.d.). Analisis Kualitas Pelayanan Jasa Kesehatan (pada Pasien Rawat Inap Rumah Sakit Pendidikan Universitas Tanjungpura Pontianak).

Affandi, H., Zaki, M., \& Azmeri. (2017). Pengaruh Kualitas Pelayanan terhadap Kepuasan Pelanggan pada Perusahaan Daerah Air 
Minum (PDAM) Tirta Mon Pase Kabupaten

Aceh Utara. Jurnal Teknik Sipil Universitas

Syiah Kuala Volume 6, Nomor 3.

Assauri, S. (2012). Strategi Marketing Sustaining

Lifetime Customer Value. Jakarta: PT. Raja Garfindo Persada.

Assegaff, M. (2009). Analisis Kualitas Pelayanan

dan Pengaruhnya terhadap Kepuasan Pelanggan. EKOBIS Vol.10, No.2 .

Bailia, J. F., Soegoto, A. S., \& Loindong, S. S. (2014). Pengaruh Kualitas Produk, Harga dan Lokasi, Terhadap Kepuasan Konsumen Pada Warung-Warung Makan Lamongan di Kota Manado. Jurnal EMBA .

Dewi, M. (2016). Pengaruh Kualiats Pelayanan kepuasan Pasien BPJS Pada Rumah Sakit Rehabilitasi Medik Kab Aceh Timur. Jurnal Manajemen Dan Keuangan Vol5 No 2 .

Febriana, N. I. (2016). Analisis Kualitas Pelayanan Bank terhadap Kepuasan Nasabah pada Bank Muamalat Indonesia Kantor Cabang Pembantu Tulung Agung. An Nisbah Vol. 03 No. 01 .

Khoirista, A., Yulianto, E., \& Mawardi, M. K. (2015). Pengaruh Kualitas Pelayanan terhadap Kepuasan Pelanggan (Survey Pada Pelanggan Fedex Express Surabaya). Jurnal Administrasi Bisnis (JAB) Vol. 25 No. 2.

Moha, S., \& Loindong, S. (2016). Analisis Kualitas Pelayanan dan Fasilitas terhadap Kepuasan Konsumen pada Hotel Yuta di Kota Manado. Jurnal EMBA Vol.4 No.1.

Nitisemito, A. S. (2001). Metode Penelitian. Jakarta: Penerbit Ghalia.

42| M. Zaky Mubarak Lubis Dan Siti Hanafiah R.
Novrialdi, J. (2017). Pelayanan Kesehatan Bagi Pasien BPJS (Badan Penyelenggara Jaminan Sosial) di Rumah Sakit Umum Daerah Kabupaten Siak Tahun 2016. JOM FISIP Vol. 4 No. 2.

Rohaeni, H., \& Marwa, N. (2018). Kualitas Pelayanan Terhadap Kepuasan Pelanggan. Jurnal Ecodemica, Vol. 2 No. 2 .

Romaji, \& Nasihah, L. (2018). Analisis Kepuasan Pasien terhadap Pelayanan Kesehatan pada Peserta Bpjs (Badan Penyelenggara Jaminan Sosial) dan Non BPJS di RSUD Gambiran Kediri Jawa Timur.

Taman, A., Sukirno, Sari, A. R., Setiawan, N., \& Pustikaningsih, A. (2013). Analisis Kualitas Pelayanan Terhadap Kepuasan Mahasiswa Pada Fakultas Ekonomi Universitas Negeri Yogyakarta. Jurnal Nominal Vol II No I .

Tjiptono, F. (2011). Service Quality and Satisfaction Edisi 3. Yogyakarta: Andi Offset.

Tjiptono, F., \& Chandra, G. (2016). Service, Quality \& Satisfaction. Yogyakarta: Andi.

Widada, T. (2017). Peran Badan Penyelenggara Jaminan Sosial (BPJS) Kesehatan dan Implikasinya Terhadap Ketahanan Masyarakat (Studi di RSUD Hasanuddin Damrah Manna, Kabupaten Bengkulu Selatan, Provinsi Bengkulu). Jurnal Ketahanan NasionalLVol.23 No.2 , Hal 199-216.

Wijaya, T. (2011). Manajemen Kualitas Jasa. Edisi 1. Jakarta: PT. Indeks.

Yansah, R. A., Hartono, B., \& Hariyono, M. (2013). Analisis kualitas pelayanan (service quality) terhadap kepuasan konsumen pada rumah makan sop ayam Pak Min Klaten di Malang. Jurnal Ilmu-Ilmu Peternakan . 